\title{
Ethical Issues in Patients with Leukemia: Practice Points and Educational Topics for the Clinical Oncologist and Trainees
}

\author{
Jeffery S Farroni ${ }^{1}$, Phillp A Thompson ${ }^{2}$, Daud Arif ${ }^{2}$, Jorge E Cortes ${ }^{2}$ and Colleen M Gallagher ${ }^{2^{*}}$ \\ ${ }^{1}$ The University of Texas Medical Branch, Galveston, Texas, USA \\ ${ }^{2}$ MD Anderson Cancer Center, The University of Texas, Houston, Texas, USA
}

"Corresponding author: Colleen M Gallagher, The University of Texas, MD Anderson Cancer Center, Section of Integrated Ethics in Cancer Care, Houston, Texas, USA, Tel: 713-792-8775; E-mail: CMGallagher@mdanderson.org

Received date: October 17, 2017; Accepted date: October 24, 2017; Published date: October 30, 2017

Copyright: (02017 Farroni JS, et al. This is an open-access article distributed under the terms of the Creative Commons Attribution License, which permits unrestricted use, distribution, and reproduction in any medium, provided the original author and source are credited.

\begin{abstract}
Leukemia represents a complex spectrum of malignancies, involving numerous treatment options and substantial symptom burden for patients. Ethical dilemmas may arise which challenge a physician's clinical management and the patient's goals of care. What is needed is the systematic analysis of the most common issues that confront clinical teams treating patients with leukemia in order to derive best ethical practices for optimized patient care. We examined 312 formal ethics consultations requested for patients with a leukemia diagnosis. We found that the most common ethical issues relate to the level of appropriate intervention, the futility of treatment and surrogate decisionmaking. The underlying causes stem from inadequately addressed psychosocial issues, disagreements between various stakeholders in the patient's care and miscommunication. Illuminating these issues provides areas of focus for the practitioner to refine their practice and inform educational initiatives. The integration of the clinical ethics service into the multidisciplinary team is a mechanism to foster a preventative ethics model and mitigate potential dilemmas.
\end{abstract}

Keywords: Leukemia; Oncology; Ethics

\section{Introduction}

A diagnosis of leukemia begins an arduous journey through a complex milieu of therapeutic options and difficult clinical decisions that may raise ethical dilemmas [1]. The disease itself is represented by a diverse array of conditions each with complex treatment algorithms, including chemotherapy, targeted therapy, stem cell transplants, etc. [2]. The impact of clinical decision making does not only affect acute treatment but also the long term care of the patient [1]. For example, patients who are very motivated to seek aggressive, potentially lifeprolonging treatment despite rather poor prognosis may not be ready for the transition to palliative or end-of-life care. High patient expectation combined with the promise of renowned technical expertise does facilitate innovative leukemia treatment. The resulting referral bias means that many of these patients seek novel therapies available on clinical trial protocols. Despite the need for pioneering disease intervention, advancing patient care must be pursued by carefully wading the waters of clinical uncertainty.

Difficult situations require practitioners to navigate all of the foundational ethical principles, i.e. respect for persons, beneficence (non-maleficence) and justice [3-5]. In an era where duty hour restrictions are in place for medical trainees and there are greater expectations of attending staff with regards to clinical productivity, ethics training for physicians often is not emphasized. Despite the paucity of time dedicated to ethics education, it has been reported that many surgical residencies support the idea of formal ethics training [6]. A survey of general surgery residency program directors, which demonstrated that $85 \%$ of them favored a standardized curriculum in ethics with content in end-of-life decision-making, managing conflict, and informed consent [6]. Interestingly resident time constraints and lack of faculty support were the primary reasons for the failure of previous ethics programs. Several other independent studies examined the success of such programs at training institutions [7]. They suggest that education on how to approach ethical dilemmas results in increased confidence in their management, and ultimately may result in improvements in patient care [7].

A clinical ethics service strives to provide clarity for dilemmas arising during the course of clinical care. Individual ethicists and ethics committee members ideally have been trained in a diversity of disciplines such as moral reasoning, bioethics, health law/policy, interpersonal dynamics, etc. [8].

This ethical imperative demands that the patient's needs transcend the interests, commitments and obligations of caregivers, physicians, society, etc. [9]. Understanding the ethical landscape in the context of leukemia treatment will better prepare the practitioner with best practices to navigate ethical dilemmas and improve patient care. Our retrospective study objectives were (1) To better describe the cases for whom ethics consultation was called, and (2) Determine which ethical themes are most common in our patient population to inform best practices and provide guidance for educational subject matter for our Leukemia Fellowship program and Leukemia attending physicians.

\section{Methods}

The Ethics Consultation Service at M. D. Anderson Cancer Center maintains a database of consults they perform. The database contains a standardized set of variables, including patient-specific demographic, clinical, and consult data (e.g. clinical ethics case type). Leukemia cases were identified as cases in which "Leukemia" was entered as either the service of the requestor or as the primary diagnosis of the patient. The clinical characteristics were validated via medical record review. Statistical analysis was conducted using SPSS software. (Version 22.0. 
Citation: Farroni JS, Thompson PA, Arif D, Corted JE, Gallagher CM (2017) Ethical Issues in Patients with Leukemia: Practice Points and Educational Topics for the Clinical Oncologist and Trainees. J Clin Res Bioeth 8: 314. doi:10.4172/2155-9627.1000314

Page 2 of 6

Armonk, NY: IBM Corp.) Non-parametric comparisons were made with Chi-square, Fisher's exact test and correspondence analysis $(\alpha=0.05)$. A grounded theory approach was used to identify themes within the ethics consultation recommendations and outcomes. Best practices were derived from an analysis of these themes. The Clinical Ethics Database Steering Committee and local Institutional Review Board approved this study.

\section{Results}

A total of 356 records, taken place between September 1993 and June 2014, identified in the Ethics Consultation Database met the study criteria. Of these, 17 records were excluded from the analysis due to incomplete information. Data analysis focused on the more common types of leukemia, namely acute lymphoblastic leukemia (ALL), acute myeloid leukemia (AML), chronic lymphocytic leukemia (CLL), chronic myeloid leukemia (CML) and myelodysplastic syndrome (MDS). Patients with rare hematological malignancies were excluded from the analysis $(n=27)$. The resulting 312 records represented $92 \%$ of useable records.

Patient demographics are summarized in Table 1. Briefly, the median age was 45 (range 3-85), with most patients either young adult $(n=113,36.2 \%)$ or middle aged $(n=100,32.1 \%)$. The majority of patients were male $(n=181,58 \%)$. Overall, patients were most likely to be married $(n=170,54.5)$, white $(n=206,66 \%)$, Christian $(n=217$, $69.5 \%)$ and live in Texas ( $\mathrm{n}=215,68.9 \%$ of U.S. residents). There was no correlation between patient demographic data and the clinical characteristics or ethical issues.

\begin{tabular}{|c|c|c|}
\hline & $\mathbf{N}$ & $\%$ \\
\hline \multicolumn{3}{|l|}{ Sex } \\
\hline Female & 131 & 42 \\
\hline Male & 181 & 58 \\
\hline Age Median (Range) & \multicolumn{2}{|c|}{$45(3-85)$} \\
\hline$<18$ & 22 & 7 \\
\hline $18-40$ & 113 & 36.2 \\
\hline $41-60$ & 100 & 32.1 \\
\hline $60-75$ & 58 & 18.6 \\
\hline$>75$ & 19 & 6.1 \\
\hline \multicolumn{3}{|l|}{ Marital Status } \\
\hline Married & 170 & 54.5 \\
\hline Single & 96 & 30.8 \\
\hline Divorced/Separated & 32 & 10.2 \\
\hline Widowed & 14 & 4.5 \\
\hline \multicolumn{3}{|l|}{ Religion } \\
\hline Christian & 217 & 69.5 \\
\hline -Catholic & 75 & $34.6^{*}$ \\
\hline -Protestant & 142 & $65.4^{*}$ \\
\hline Jewish & 18 & 5.8 \\
\hline
\end{tabular}

\begin{tabular}{|c|c|c|}
\hline Muslim & 11 & 3.5 \\
\hline Other & 5 & 1.6 \\
\hline No Preference/None Stated & 61 & 19.6 \\
\hline \multicolumn{3}{|l|}{ Race } \\
\hline White & 206 & 66 \\
\hline Black & 46 & 14.7 \\
\hline Hispanic & 44 & 14.5 \\
\hline Asian & 11 & 3.5 \\
\hline Other/Unknown & 4 & 1.3 \\
\hline \multicolumn{3}{|l|}{ Residence } \\
\hline U.S. & 287 & 92 \\
\hline -Texas & 215 & $68.9+$ \\
\hline -Rest of US & 72 & $32.1 \dagger$ \\
\hline International & 22 & 8 \\
\hline \multicolumn{3}{|l|}{ Payor Group } \\
\hline 3rd Party Insurance & 127 & $40.7 \ddagger$ \\
\hline Federal/State & 102 & $32.7 \S$ \\
\hline Indigent/Uncompensated Care & 42 & 13.4 \\
\hline Self-pay & 37 & $11.9 \pi$ \\
\hline Not Specified & 4 & 1.3 \\
\hline \multicolumn{3}{|l|}{ Primary Language } \\
\hline English & 274 & 87.8 \\
\hline Spanish & 20 & 6.4 \\
\hline Other & 18 & $5.8+\dagger$ \\
\hline \multicolumn{3}{|c|}{$\begin{array}{l}\text { *Indicates the percentage of the total number of Christian patients. †Indicates } \\
\text { the percentage of patients residing within the United States. } ¥ \text { Third party } \\
\text { insurance includes employer-provided and commercial. §This category includes } \\
\text { Medicare, Medicaid and local, state funded support. शThis category includes } \\
\text { insurance denial and shortage of benefits. † †ther languages include Turkish, } \\
\text { Arabic, Chinese, Vietnamese, French, Greek, and sign language. }\end{array}$} \\
\hline
\end{tabular}

Table 1: Demographic information of ethics consultations in patients with leukemia at a tertiary cancer center $(n=312)$.

The clinical characteristics are summarized in Table 2. AML was the most common diagnosis $(\mathrm{n}=140,44.9 \%)$ with most patients having received either one or two prior therapies at the time of the ethics consultation ( $n=161,51.6 \%$ and $n=88,28.2 \%$ respectively). Statistically significant age-related differences occurred in the incidence of AML, ALL and CML diagnoses $\chi^{2}(8, n=253)=21.031 \quad(\alpha<0.01)$. Also, the majority of patients had previously received a stem cell transplant $(\mathrm{n}=179,57.4 \%)$.

\begin{tabular}{|c|c|c|}
\hline & $\mathbf{N}$ & $\%$ \\
\hline \multicolumn{3}{|c|}{ Diagnosis $†$} \\
\hline AML & 140 & 44.9 \\
\hline
\end{tabular}


Citation: Farroni JS, Thompson PA, Arif D, Corted JE, Gallagher CM (2017) Ethical Issues in Patients with Leukemia: Practice Points and Educational Topics for the Clinical Oncologist and Trainees. J Clin Res Bioeth 8: 314. doi:10.4172/2155-9627.1000314

Page 3 of 6

\begin{tabular}{|l|l|l|}
\hline ALL & 74 & 23.7 \\
\hline CML & 39 & 12.5 \\
\hline CLL & 35 & 11.2 \\
\hline MDS & 24 & 7.7 \\
\hline
\end{tabular}

\section{Prior Treatments}

\begin{tabular}{|l|l|l|}
\hline 0 & 8 & 2.6 \\
\hline 1 & 161 & 51.6 \\
\hline 2 & 88 & 28.2 \\
\hline 4 & 21 & 6.7 \\
\hline$>4$ & 7 & 2.2 \\
\hline
\end{tabular}

\section{Stem Cell Transplant}

\begin{tabular}{|l|l|l|}
\hline Yes & 133 & 42.6 \\
\hline No & 179 & 57.4 \\
\hline
\end{tabular}

\section{Survivorł}

\begin{tabular}{|l|l|l|}
\hline Yes & 33 & 10.6 \\
\hline No & 279 & 89.4 \\
\hline
\end{tabular}

${ }^{*}$ Data are as of the ethics consultation date, unless specified otherwise. †Acute lymphoblastic leukemia (ALL), acute myeloid leukemia (AML), chronic lymphocytic leukemia (CLL), chronic myeloid leukemia (CML) and myelodysplastic syndrome (MDS). $\ddagger$ As of the data extraction date.

Table 2: Clinical characteristics of ethics consultations requested on patients with leukemia at a tertiary cancer center $(\mathrm{n}=312)^{*}$.

Most ethicists deemed requests for consultation to be at an appropriate time $(\mathrm{n}=241,77.2 \%)$. A consultation is deemed 'appropriate' when the ethical issue is both ripe and actionable. The ethics consultation database allows ethicists to assign up to five a priori categorizations to describe the ethical issue(s) presented in the consultation. The number of identifiable issues is used as an indirect marker for case complexity. The vast majority of cases were deemed to have up to three issues $(\mathrm{n}=275,88.1 \%)$ with most cases having two issues $(n=119,38.1)$. The four most common issues were deciding on the level of appropriate treatment $(n=161,23.7 \%)$, determining the surrogate decision-maker $(n=112,16.5 \%)$, the futility of further aggressive interventions $(\mathrm{n}=86,12.7 \%)$ and patient non-adherence to the clinical plan $(n=59,8.7 \%)$. More details summarizing the ethics consultations can be found in Table 3 .

\begin{tabular}{|l|l|l|}
\hline Consult Timing & $\mathbf{( N = 3 1 2 )}$ & \\
\hline Requested too Early & 11 & 3.5 \\
\hline Appropriate Timing & 241 & 77.2 \\
\hline Requested too Late & 38 & 12.2 \\
\hline Unspecified & 22 & 7.1 \\
\hline Case Complexity & $\mathbf{( N = 3 1 2 )}$ & \\
\hline 1 & 84 & 26.9 \\
\hline
\end{tabular}

\begin{tabular}{|l|l|l|}
\hline 2 & 119 & 38.1 \\
\hline 3 & 72 & 23.1 \\
\hline 4 & 25 & 8 \\
\hline 5 & 8 & 2.6 \\
\hline Unspecified & 4 & 1.3 \\
\hline Issues Identified* & $\mathbf{( N = 6 7 8 )}$ & \\
\hline Level of Appropriate Treatment & 161 & 23.7 \\
\hline Surrogate Decision Making & 112 & 16.5 \\
\hline Futility & 86 & 12.7 \\
\hline Non-adherence to Clinical Plan & 59 & 8.7 \\
\hline Quality of Life & 46 & 6.8 \\
\hline Informed Consent & 43 & 6.3 \\
\hline Resource Utilization/Organizational Ethics & 34 & 5 \\
\hline Advanced Directives & 31 & 4.6 \\
\hline Discharge & 91 & 2.2 \\
\hline Other & 15.4 \\
\hline *Issues are greater than the number of consultations due to multiple issues \\
\hline identified per consult. & & \\
\hline & & 5 \\
\hline
\end{tabular}

Table 3: The timing, complexity and diversity of ethics consultation in patients with leukemia $(\mathrm{N}=312)$.

A relationship arose between a diagnosis of AML and the occurrence of an ethics consult involving the issues of surrogate decision making and non-adherence to the clinical plan $\chi^{2}(12$, $n=201)=23.286(\alpha=0.025)$. The issue of futility was more closely associated with a diagnosis of ALL and CML $\chi^{2}(12, n=201)=23.286$ $(\alpha=0.025)$. Complex cases, i.e. those involving multiple issues, involved the issues of both the level of appropriate care and the futility of further medical intervention $\chi^{2}(12, n=199)=26.354(\alpha=0.01)$.

Along with the case type, ethicists are also able to record the underlying issues that contribute to the dilemma or conflict at hand. Underlying issues are summarized in Table 4. The four most common underlying issues are insufficient psychosocial support ( $n=195,31.4 \%)$, disagreements between parties most notably between the medical team and patient caregivers $(n=143,23.0 \%)$, communication barriers $(n=96$, $15.5 \%)$ and consult requestor support $(n=64,10.3 \%)$. Support in this instance ranges from validation of difficult decisions that have already been made to coping. Psychosocial issues include complex and/or conflicting family dynamics, spiritual issues and cultural barriers to care.

\begin{tabular}{|c|c|c|}
\hline & $\mathbf{N}$ & $\%$ \\
\hline \multicolumn{3}{|l|}{ Underlying Issues } \\
\hline Psychosocial Issues & 195 & 31.4 \\
\hline Disagreement between Parties & 143 & 23 \\
\hline Communication Issues & 96 & 15.5 \\
\hline
\end{tabular}




\begin{tabular}{|l|l|l|}
\hline Support & 64 & 10.3 \\
\hline Legal Risk & 47 & 7.6 \\
\hline System Issues & 39 & 6.3 \\
\hline Goals of Care & 16 & 2.6 \\
\hline Other & 21 & 3.4 \\
\hline
\end{tabular}

and reach a consensus regarding when to transition care. In this case, the family agreed to allow a reasonable time to assess the effectiveness of anti-viral therapy.

A final representative case highlights the utility of employing the expertise of the multidisciplinary team to address ethical dilemmas. The medical team strongly felt the patient would benefit by participating in a clinical trial but the patient and her partner were less certain. The stalemate was costing precious time and uncertainty with regards to developing the best plan of care. Part of this uncertainty was expressed by the partner who was expressing anticipatory grief that his "loved one was dying and if her wishes would be honored." He was having difficulty "cope[ing] with her illness" and being "alone in Houston for her treatment." Through the consult we, along with a social worker, were able to address some of these coping and support issues in order for the patient and her partner to choosing the best course moving forward. representational cases that illustrate these themes. One case involved the determination of whether or not the patient should continue ventilator support and code status. The medical team was becoming increasingly uncomfortable with continued ventilator support and full code status upon the insistence of the family's "hope for a miracle" and desire to "give him every possible chance (to live)." During the ethics consultation, a deeper discussion of the patient's values revealed that "if the ventilator were the only thing keeping him alive, then we should get rid of it." The team was able to clarify the patient's condition and prognosis for the family and convey more realistic expectations which resulted in a plan of care better harmonized to the patient's values.

Another example involved a disagreement between the medical team and the patient with regards to the transition from curative to palliative care. A patient, diagnosed with CLL post two allogenic stem cell transplants, was admitted to the critical care unit for viral encephalopathy. The patient did not have decisional capacity and the wife wanted to transition the patient to comfort care despite the medical team's desire to continue to treat the infection to see if the patient would recover. During the consultation meeting, both the team and the patient's family were able to discuss each other's expectations

\section{Discussion}

Treating diseases like leukemia in which a standard of care may not exist, increases the need to understand ethical dilemmas that frequently present themselves to the medical team. This study suggests that an ethics consultation is called when the limits of medical intervention are reached and the discernable preferences of the patient become opaque to the medical team. The most prevalent issues are those that involve difficult decision-making (sometimes by someone other that the patient) and whether or not further medical interventions are possible or desired. The dynamic nature of diseases like leukemia coupled with innovative approaches to care and evolving patient expectations underscore the importance of understanding and addressing ethical dilemmas as they arise. This reaffirms the importance of communication with the patient and discernment of the patient's values and preferences when developing a plan of care. Best practices that may mitigate the ethical issues presented in these cases include fostering trust though strategies that encourage communication and shared decision-making (Table 5).

1. Foster open communication including by setting reasonable expectations in alignment with patient's values and goals.

2. Establish trigger events for communicating with the patient, e.g. revisit the plan of care when a significant change in the patient's condition occurs.

3. Discuss goals of care often and early, including when to transition care, e.g. curative to palliative.

4. Utilize a multidisciplinary approach that leverages the expertise of the clinical team to discern a deeper understanding of the patient's values, beliefs and expectations, e.g. contacting the hospital ethicist or ethics committee for assistance in cases that pose challenging ethical dilemmas.

Table 5: Practice points for mitigating ethical dilemmas in patients with leukemia.

Encouraging ethical best practices in these circumstances can be achieved through two key initiatives: (1) developing educational curricula that highlight and create a space to reflect on these issues and (2) fostering an integrated approach to ethics that incorporates that expertise into the multidisciplinary team.

\section{Refining ethics educational objectives}

The positive impact on patient care is predicated on the recognition that both the clinical team and the patient embody the core ethical principles outlined above. For example, one way which we recognize the respect for persons is through honoring a patient's autonomy to make their own medical decisions [10]. One way in which we recognize beneficence is through the physician's risk/benefit analysis regarding which interventions are appropriate, inappropriate or futile. Knowing which issues are not only most prevalent but most challenging (hence the request for consultation) is important for developing best ethical practices. Here we will examine two: patient autonomy and futility.

Even in the setting of optimal communication, however, differences of opinion may arise surrounding treatment decisions between patients or surrogate decision makers and their physicians. Physicians must carefully weigh the risks and benefits of an intervention when determining the plan of care. Difficult-to-treat diseases like leukemia are often treated aggressively, where the harm of not providing treatment is magnified and there is no standard-of-care [11]. Two 
potential conflicts may arise: firstly a patient or surrogate may request treatment that their physician may feel is medically futile, as a result of the extremely low likelihood that the treatment will result in substantial benefit for the patient and/or would be more likely to harm than benefit the patient [12]; secondly, a patient may refuse treatment the physician feels is potentially lifesaving.

Historically, the prevailing medical perspective was that physicians made decisions, albeit with beneficent intent, that involved little active participation from the patient [13]. In fact, many physicians would most likely not inform a patient they had cancer and treat the patient purely in the context of their sounds medical judgment [14]. Problems with excessive paternalism include difficulties determining the patient's best interest [15] and biases due to patient demographic characteristics $[16,17]$.

Over the past few decades there has been a shift from medical paternalism to a model of respecting the patient's autonomy to make their own, informed medical decisions [18]. This shift has been driven by numerous factors, including the problems with a paternalistic model outlined previously, the consumer movement [19] and fear from the physician of law-suits if treatment based on the physician's opinion results in an adverse outcome [20]. The consumer movement, combined with an explosion of easily-available information, leads in some cases to patients requesting treatment which the physician may feel is inappropriate [19].

In a truly autonomous model of decision-making, the patient is presented with clinical options by the physician and makes a choice regarding his or her treatment without the influence of the physician's opinion. This "patient-centered" model requires physicians avoid biasing the patient's decision by offering their personal opinion [21]. There remain ethical questions surrounding the appropriateness of allowing a patient to choose futile treatment $[22,23]$ and to continue it in the absence of benefit [24].

Others have suggested an "enhanced autonomy" model, whereby the physician informs patients of treatment options and probability of success, explores the patient's values and their own and then offers recommendations considering both the patient and physician's values and experiences [25]. They argue that the physician's opinion enhances the autonomous medical choices made by the patient rather than undermining them and reduces the likelihood of inappropriate treatments being requested by the patient as a result of inadequate understanding [25].

There was an observed concordance for some types of leukemia of the level of appropriate treatment and the futility of intervention. The issue of medical futility is complex. It requires a judgment to be made regarding the statistical likelihood of survival or successful treatment, which, even when data based on large numbers of patients is available, may be difficult to ascertain in an individual case [26]. It also may require a judgment regarding what degree of quality of life would be achievable through successful treatment and would be acceptable to the patient. Finally, the subjective nature of quality-of-life assessment by a physician creates substantial potential for disagreement between the patient/surrogate and health care providers [12]. This inherently contains a measure of subjectivity and the patient's opinion may differ from that of the physician. While in the past major public policy statements have supported the right of a physician to decide to withhold inappropriate treatment on the basis of medical futility [27], a precise definition of futility is elusive. There is no agreement regarding the odds of failure required for a treatment to be considered futile and any "cut-off" is inherently arbitrary [28,29]. The issue of futility may be clarified by shifting the perspective to the appropriateness of care [30]. Futility, it can be argued, is only determined in retrospect rendering it an impractical concept whereas a focus on 'appropriateness' may provide for setting more concrete interventional boundaries [30].

Providing futile medical treatment may cause un-necessary harm to a patient; the principle of justice provides an ethical duty to physician not to administer such futile therapy [31]; additionally, requests of nursing staff to provide care that they feel is contrary to the best interests of the patient compromises their professional integrity and can result in conflicts within the health care team [32]; finally, in a situation of limited resources (such as ICU beds), physicians have a duty to appropriately allocate these resources to patients who may benefit from them [33].

This study suggests that clinicians treating patients with leukemia face, and seek guidance on, these ethical challenges particularly when it comes to weighing risk/benefit after multiple interventions have failed and patient preference are unclear. Centering ethics education to the specialty-centered needs of physicians and trainees on issues like risk/benefit assessment, the appropriateness of intervention, caring for the whole patient, and shared decision making will facilitate the embodiment of ethical norms and improve patient care.

\section{Integrating ethics into multidisciplinary practice}

Ethics consultation is a mechanism to improve the quality of health care through analysis and resolution of ethical concerns. It can illuminate some of the broader issues based upon a sound framework. One popular model of ethical analysis involves the incorporation of the clinical component as well as the quality of life, patient preferences and contextual features [4]. What is important in this, and similar, models is the recognition that ethical decision making extends beyond what can be done clinically to what ought to be done within the broader context of the whole patient. There has been a fundamental shift in the process of medical decision-making in the past 40 years.

For the last 30 years, ethics consultation has been an important part of clinical medicine. Beyond simply enhancing the impact of patient preferences in medical decision-making, ethics consults protect patient rights, help resolve conflicts between parties involved in patient care, and provide moral support to both patient and staff $[34,35]$. Additionally, ethics consults have been shown to reduce hospital and intensive care unit (ICU) stays, as well as promote the withdrawal of non-beneficial life sustaining measures [36]. Because of the success of ethics consultation services, it is now estimated that they exist in $81 \%$ or more of hospitals in the United States and that more than 314,000 h are dedicated to ethics consults annually [34].

The commonly occurring underlying issues fall under the domain expertise of not only the ethicist but also the multidisciplinary team at large. For example, the psychosocial needs that presented in these ethics consultations included cultural barriers, spiritual needs and family dynamics. In cases like these, the ability of the medical team to leverage such disciplines as ethics, chaplaincy and social work will provide much needed support to help mitigate potential conflicts. The therapeutic relationship between patient and physician can be damaged when differences in opinion regarding the plan of care cannot be resolved through open and candid dialogue. Many of these cases involved miscommunication that may have been clarified 
through the distinctive lens employed by members of the interdisciplinary team.

A limitation to this study is that it represents the collective work of twenty-two ethics consultants over a twenty-one year span. There are subjective differences in how individual ethicists categorize consult issues. Future work will involve establishing harmonized issue categorization to reduce subjectivity. Other initiatives will more closely examine specific clinical features within this patient population and respective substantive elements of the ethics consultations.

Leukemia treatment poses many complex moral and ethical dilemmas ranging from the limits of clinical intervention, managing patient expectations, meeting patient goals, coping with suffering, etc. Insight into the most common types of ethical issues provides a substrate to build a foundation for continued development in ethical clinical practice. Knowing to anticipate and mitigate potential dilemmas and having a multidisciplinary team with specific domain expertise to assist in managing patient concerns will translate into improved patient care.

\section{References}

1. Shannon-Dorcy K, Wolfe V (2003) Decision-making in the diagnosis and treatment of leukemia. Semin Oncol Nurs 19: 142-149.

2. Kantarjian H, Wolff RA, Koller CA (2011) The MD Anderson manual of medical oncology. 2nd ed, New York: McGraw-Hill, Medical Pub. xxii, $1400 \mathrm{p}$.

3. Beauchamp TL, Childress JF (2013) Principles of biomedical ethics. 7th ed, New York: Oxford University Press. xvi, 459 p.

4. Jonsen AR, Siegler M, Winslade WJ (2010) Clinical ethics : a practical approach to ethical decisions in clinical medicine. 7th ed, New York: McGraw-Hill Medical. vi, 228 p.

5. Rothman DJ (2008) Strangers at the bedside : a history of how law and bioethics transformed medical decision making. New Brunswick NJ: AldineTransaction.

6. Downing MT, Way DP, Caniano DA (1997) Results of a national survey on ethics education in general surgery residency programs. Am J Surg 174: 364-368.

7. Helft PR, Eckles RE, Torbeck L (2009) Ethics education in surgical residency programs: a review of the literature. J Surg Educ 66: 35-42.

8. Core Competencies for Healthcare Ethics Consultation (2011) 2nd ed. American Society for Bioethics and Humanities.

9. Freireich EJ (1997) Who took the clinical out of clinical research?--Mouse versus man: seventh David A Karnofsky Memorial Lecture--1976. Clin Cancer Res 3: 2711-2722.

10. United States. National Commission for the Protection of Human Subjects of Biomedical and Behavioral Research., The Belmont report : ethical principles and guidelines for the protection of human subjects of research. DHEW Publication no (OS) 78-0012. 1978, Bethesda, Md., Washington. $20 \mathrm{p}$.

11. Kantarjian H, Stewart DJ, Zwelling L (2013) Cancer research in the United States: dying by a thousand paper cuts. Cancer 119: 3742-3745.

12. Bernat JL (2005) Medical futility: definition, determination, and disputes in critical care. Neurocrit Care 2: 198-205.

13. Emanuel EJ, Emanuel LL (1992) Four models of the physician-patient relationship. JAMA 267: 2221-2226.
14. Oken D (1961) What to tell cancer patients. A study of medical attitudes. JAMA 175: 1120-1128.

15. Schneiderman LJ (1993) Do physicians' own preferences for lifesustaining treatment influence their perceptions of patients' preferences? J Clin Ethics 4: 28-33.

16. Burstin HR, Lipsitz SR, Brennan TA (1992) Socioeconomic status and risk for substandard medical care. JAMA 268: 2383-2387.

17. Blendon RJ, Aiken LH, Freeman HE, Corey CR (1989) Access to medical care for black and white Americans. A matter of continuing concern. JAMA 261: 278-281.

18. Lazare A, Eisenthal S, Wasserman L (1975) The customer approach to patienthood. Attending to patient requests in a walk-in clinic. Arch Gen Psychiatry 32: 553-558.

19. Barsky A (1988) Worried sick: Our Troubled Quest for Wellness. Boston: Little, Brown.

20. Gutheil TG, Bursztajn H, Brodsky A (1984) Malpractice prevention through the sharing of uncertainty. Informed consent and the therapeutic alliance. N Engl J Med 311: 49-51.

21. Brody H (1985) Autonomy revisited: progress in medical ethics: discussion paper. J R Soc Med 78: 380-387.

22. Schneiderman LJ, Jecker NS, Jonsen AR (1990) Medical futility: its meaning and ethical implications. Ann Intern Med 112: 949-954.

23. Truog RD, Brett AS, Frader J (1992) The problem with futility. N Engl J Med 326: 1560-1564.

24. Angell M (1991) The case of Helga Wanglie. A new kind of "right to die" case. N Engl J Med 325: 511-512.

25. Quill TE, Brody H (1996) Physician recommendations and patient autonomy: finding a balance between physician power and patient choice. Ann Intern Med 125: 763-769.

26. Truog RD (1992) Can empirical data establish futility? J Clin Ethics 3: 315-316

27. Guidelines for the appropriate use of do-not-resuscitate orders. Council on Ethical and Judicial Affairs, American Medical Association. JAMA (1991) 265: 1868-1871.

28. Lantos JD, Singer PA, Walker RM, Gramelspacher GP, Shapiro GR, et al. (1989) The illusion of futility in clinical practice. Am J Med 87: 81-84.

29. Prendergast TJ (1995) Futility and the common cold. How requests for antibiotics can illuminate care at the end of life. Chest 107: 836-844.

30. Ewer MS (2001) The definition of medical futility: Are we trying to define the wrong term? Heart Lung 30: 3-4.

31. Jecker NS, Schneiderman LJ (1993) Medical Futility: The Duty Not to Treat. Camb Q Healthc Ethics 2: 151-159.

32. Brody H (1994) The physician's role in determining futility. J Am Geriatr Soc 42: 875-878.

33. Jecker NS, Schneiderman LJ (1992) Futility and rationing. Am J Med 92: 189-196.

34. Fox E, Myers S, Pearlman RA (2007) Ethics consultation in United States hospitals: a national survey. Am J Bioeth 7: 13-25.

35. Nilson EG, Acres CA, Tamerin NG, Fins JJ (2008) Clinical ethics and the quality initiative: a pilot study for the empirical evaluation of ethics case consultation. Am J Med Qual 23: 356-364.

36. Schneiderman LJ, Gilmer T, Teetzel HD, Dugan DO, Blustein J, et al. (2003) Effect of ethics consultations on nonbeneficial life-sustaining treatments in the intensive care setting: a randomized controlled trial. JAMA 290: 1166-1172. 